\title{
Studi Pergerakan Gelombang Kelvin Berdasarkan Analisis SLA (Sea Level Anomaly) di Samudra Hindia
}

\author{
Louis Jannahtuna'im Koes Miranda*, Muhammad Helmi, Hariyadi, Anindya Wirasatriya, Purwanto \\ Departemen Oseanografi Fakultas Perikanan dan Ilmu Kelautan, Universitas Diponegoro \\ Jl. Prof. Sudarto No. 13 Tembalang, Kec. Tembalang, Kota Semarang, Jawa Tengah 50275 \\ Email: *louisjkmiranda@gmail.com
}

\begin{abstract}
Abstrak
Gelombang Kelvin merupakan fenomena gelombang di laut yang dipengaruhi gaya gravitasi bumi dan terperangkap di daerah ekuator. Pada Ekuator Samudera Hindia terjadi awal kebangkitan Gelombang Kelvin yang kemudian bergerak ke arah timur yaitu masuk ke Perairan Indonesia diantaranya Perairan Barat Sumatera, Perairan Selatan Jawa dan Bali, dan Perairan Selatan Nusa Tenggara. Tujuan penelitian ini yaitu mengkaji variabilitas SLA (Sea Level Anomaly) serta mengkaji hubungan keduanya terhadap Gelombang Kelvin di perairan Selatan Jawa dengan menggunakan data perekaman harian tahun 2014 - 2019 untuk masing-masing parameter. Penelitian dilakukan dengan analisis sebaran spasial dan temporal untuk diagram Hovmöller. Hasil penelitian ini menunjukkan bahwa potensi Gelombang Kelvin di Perairan Selatan Jawa terdapat 3 sinyal yang tertangkap berdasarkan variabilitas SLA. Selain itu, terdapat keterkaitan yang searah antara Gelombang Kelvin dengan pergerakan SLA positif. Rata-rata nilai SLA positif berkisar pada $0,1-0,3 \mathrm{~m}$ dengan kecepatan sebesar $1 \mathrm{~m} / \mathrm{s}$.
\end{abstract}

Kata kunci : Gelombang Kelvin, Anomali Tinggi Permukaan Laut, Diagram Hovmoller

Abstract

Kelvin waves is a planetary wave in the ocean that is influenced by the earth's gravitational force and are trapped in the equatorial region. At the Equator of the Indian Ocean, there is an awakening of the Kelvin Wave which then moves to the east, entering Indonesian waters including the West Sumatra Waters, the Southern Waters of Java and Bali, and the Southern Waters of Nusa Tenggara. The purpose of this study is to examine the variability of SLA (Sea Level Anomaly) and to examine the relationship between the two of Kelvin Waves in Sauthern Java waters using 2014 - 2019 daily recording data for each parameter. The research was conducted by analyzing the spatial and temporal distribution for the Hovmöller diagram. The results indicate 3 signals of the potential for Kelvin Waves in the Southern Waters of Java. In addition, there is a direct relationship between Kelvin Waves and positive SLA. The mean positive SLA values ranged from $0.1-0.3 \mathrm{~m}$ with speed of $1 \mathrm{~m} / \mathrm{s}$.

Keywords : Kelvin waves, Sea Level Anomaly (SLA), Hovmoller Diagram

\section{PENDAHULUAN}

Samudra Hindia yang didalamnya termasuk perairan Indonesia merupakan suatu perairan yang iklimnya sangat dipengaruhi oleh fenomena El Nino. El Nino berpengaruh terhadap parameter hidrofisikal dan sirkulasi di atmosfer pada musim northeastern monsoon (Byshev et al., 2012). Menurut Wang and Weisberg (2001) anomali angin baratan yang diakibatkan oleh El Nino memicu terbentuknya Gelombang Kelvin Ekuatorial, yang penjalarannya dari barat Samudra Hindia ke Perairan Barat Sumatra. Gelombang Kelvin Ekuatorial menekan thermoklin dan menyebabkan suhu permukaan laut meningkat. Akibatnya, angin baratan anomali bertambah pada tengah Samudera Hindia dengan meningkatkan gradien tekanan di atmosfer.

Gelombang Kelvin Ekuatorial adalah gelombang gravitasi berskala besar yang dipengaruhi oleh rotasi bumi dan tertangkap di Equator. Keberadaan gelombang Kelvin Ekuatorial tergantung pada gravitasi, akselerasi Coriolis, dan batas vertikal dari ekuator. Peran Gelombang Kelvin Ekuatorial di laut saling bersinggungan dengan pergerakan pasang surut, tekanan angin pada perairan tropis, dan ENSO (Wang and Weisberg 2001). Gelombang Kelvin Ekuatorial juga memiliki amplitudo yang tinggi dan periode yang relatif lama (Delcroix et al., 2000).

Menurut teori Holton and Lindzen (1968); Matsuno (1966); Wallace and Kousky (1968), pergerakan gelombang Kelvin Ekuatorial ini searah dengan perambatan angin. Sprintall et al., (2003) menyatakan pada 
musim peralihan, terdapat angin dari barat di wilayah Ekuator yang menimbulkan munculnya Gelombang Kelvin Ekuatorial ke arah timur. Gelombang Kelvin Ekuatorial yang berasal dari Ekuator Samudera Hindia akan bergerak ke arah timur yaitu masuk ke Perairan Indonesia (Durland and Qiu 2003; Wang and Weisberg 2001) menjelaskan bahwa Gelombang Kelvin Ekuatorial bersifat unidirectional yaitu pergerakannya hanya ke satu arah, sehingga ketika Gelombang Kelvin Ekuatorial yang bergerak ke bagian barat Perairan Pulau Sumatera cenderung akan berbelok ke bagian selatan Perairan Indonesia yaitu Perairan Jawa, Bali, dan Nusa Tenggara. Banyaknya fenomena oseanografi lainnya yang terjadi di Perairan Samudra Hindia membuat penelitian Gelombang Kelvin pada daerah tersebut untuk diketahui seberapa besar potensinya.

\section{MATERI DAN METODE}

Pengolahan dan analisis dilakukan pada Bulan Juni 2020 - April 2021. Pengolahan dan analisis dilakukan di Laboratorium Pusat Kajian Mitigasi Bencana Pesisir dan Laut (CoREM) UPT Laboratorium Terpadu Universitas Diponegoro. Lokasi Penelitian dilakukan pada Samudra Hindia hingga wilayah Selatan Jawa dengan koordinat $42^{\circ} \mathrm{BT}-118^{\circ} \mathrm{BT}$ dan $13^{\circ} \mathrm{LU}-18^{\circ} \mathrm{LS}$ yang dapat dilihat pada Gambar 1 .

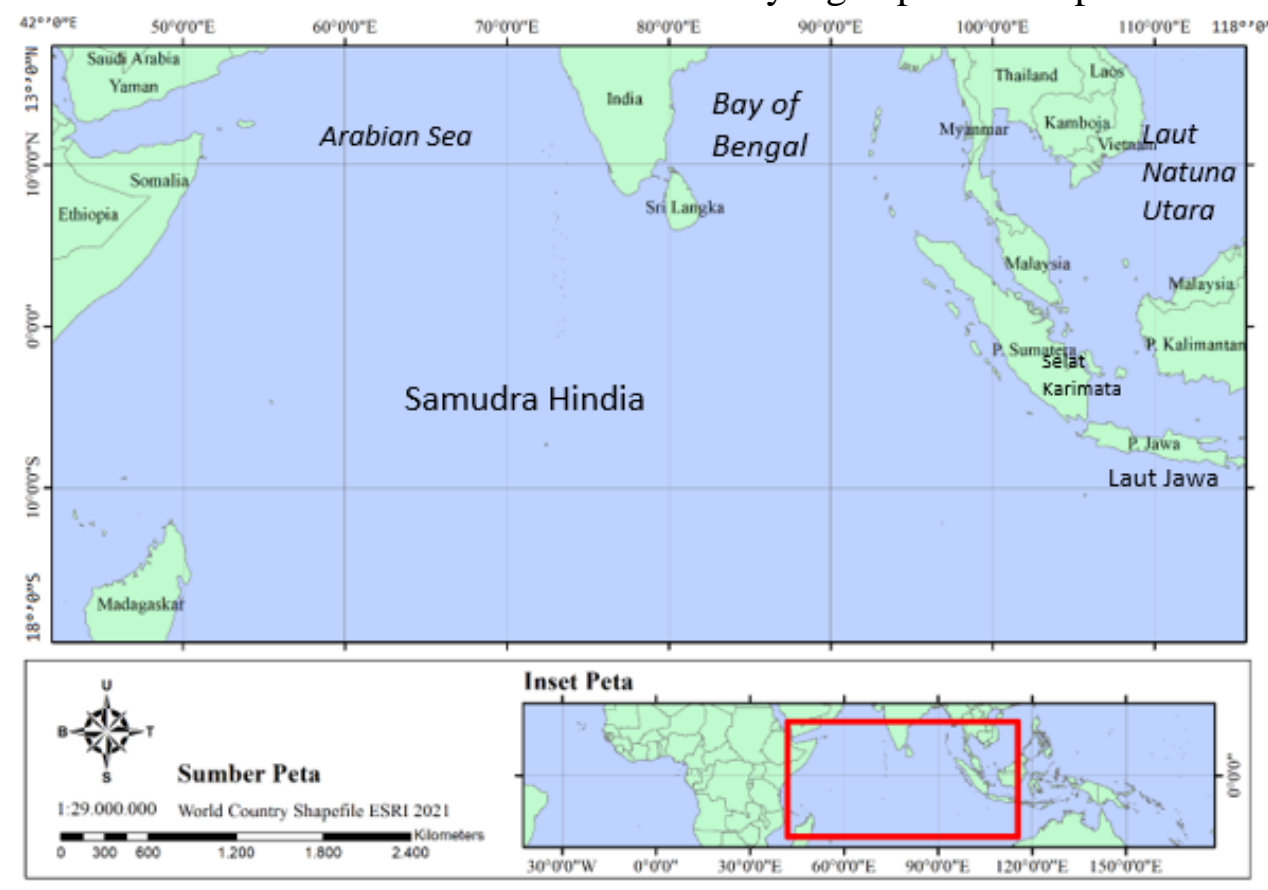

Gambar 1. Peta Lokasi Penelitian

Data yang digunakan adalah data SLA (Sea Level Anomaly) dari Copernicus Marine Environment Monitoring Service (CMEMS) dari tahun 2014 hingga 2019. Data tersebut merupakan data observasi satelit. Data SLA (Sea Level Anomaly) didapatkan dari CMEMS dengan resolusi $0.25^{\circ}$ x $0.25^{\circ}$ yang dapat diunduh dari ftp.sitac.cls.fr. Data tersebut memiliki format NetCDF atau NC File.

Data SLA (Sea Level Anomaly) yang dipakai merupakan data selama 5 tahun (2014 - 2019). Data yang telah diunduh kemudian diolah pada Bahasa pemrograman dengan mengkompilasi secara bulanan kemudian secara klimatologi dengan rumus berikut :

$$
\bar{x} b(x, y)=\frac{1}{m h} \sum_{i=1}^{m h} x i(x, y, t)
$$

Keterangan: 


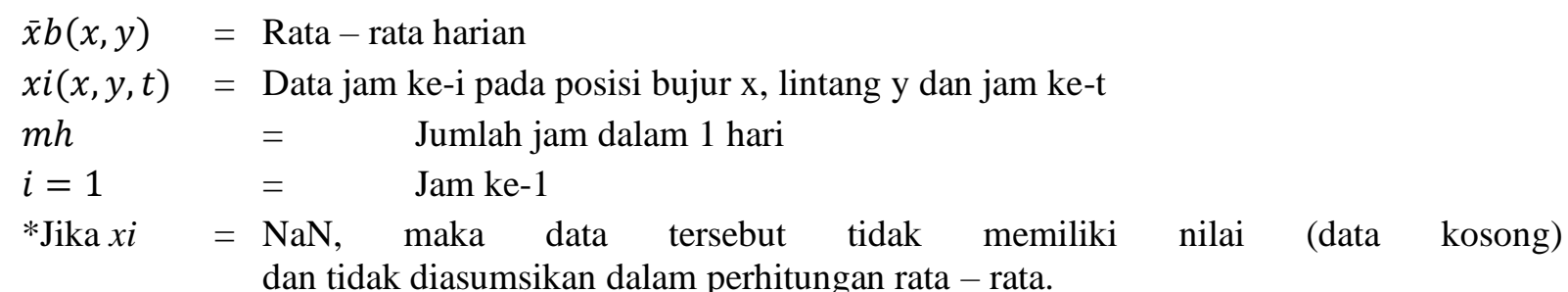

(Wirasatriya et al., 2017)

Komposit bulanan dilanjutkan menjadi peta hovmoller menggunakan data komposit bulanan. Peta hovmoller dapat mengetahui tentang keberadaan SLA (Sea Level Anomaly) positif yang menjadi salah satu indikasi mengenai keberadaan gelombang kelvin. Peta SLA (Sea Level Anomaly) dan diagram hovmoller *png dan *tiff.

\section{HASIL DAN PEMBAHASAN}

Sepanjang Ekuator Samudera Hindia hingga Perairan Barat Sumatera pada SLA, yang dideskripsikan secara spasial tiap bulannya dari tahun 2014 - 2019, menunjukkan variabilitas SLA yang cenderung positif selama bergerak dari barat ke timur. Gelombang Kelvin di perairan berhubungan erat dengan nilai SLA yang positif.

Analisis tabel ini dilakukan dengan menggunakan jarak dan waktu penjalaran SLA (Sea Level Anomaly) yang didapatkan dari grafik hovmoller pada musim peralihan I dan musim peralihan II tahun 20142019. Didapatkan hasil bahwa pada musim peralihan I tahun 2014-2019 didapatkan kecepatan berturut - turut $1.03,0.89,1.02,0.89,0.89$, dan $1.03 \mathrm{~m} / \mathrm{s}$. dan didapatkan pada musim peralihan II tahun 2014-2019 rata - rata bernilai $0.998 \mathrm{~m} / \mathrm{s}$.

Tabel 1. Tabel Perhitungan kecepatan Gelombang Kelvin

\begin{tabular}{|l|r|r|r|}
\hline Sebaran SLA Positif & Jarak (m) & waktu (s) & kecepatan (m/s) \\
\hline Musim Peralihan I 2014 & 7936500 & 7689600 & 1.032108302 \\
\hline Musim Peralihan II 2014 & 7936500 & 7948800 & 0.998452597 \\
\hline Musim Peralihan I 2015 & 6882000 & 7689600 & 0.894975031 \\
\hline Musim Peralihan II 2015 & 7935500 & 7947800 & 0.998452402 \\
\hline Musim Peralihan I 2016 & 7936500 & 7689600 & 1.032108302 \\
\hline Musim Peralihan II 2016 & 7936500 & 7948800 & 0.998452597 \\
\hline Musim Peralihan I 2017 & 6438000 & 7689600 & 0.837234707 \\
\hline Musim Peralihan II 2017 & 7936500 & 7948800 & 0.998452597 \\
\hline Musim Peralihan I 2018 & 6493500 & 7689600 & 0.844452247 \\
\hline Musim Peralihan II 2018 & 7936500 & 7948800 & 0.998452597 \\
\hline Musim Peralihan I 2019 & 7936500 & 7689600 & 1.032108302 \\
\hline
\end{tabular}

Menurut Drushka et al., (2010) diketahui bahwa gelombang Kelvin memiliki kecepatan sebesar 1$3 \mathrm{~m} / \mathrm{s}$ dengan waktu propagasi selama 20 hari melewati Samudra Hindia dan 10 hari berpindah ke laut Indonesia. Dengan melihat Tabel 1, dapat diketahui bahwa terdapat 3 kejadian gelombang Kelvin dimana terjadi pada musim peralihan I tahun 2014, musim peralihan I pada tahun 2016 dan musim peralihan I pada tahun 2019. Variabilitas SLA positif yang cenderung tinggi didominasi pada musim Peralihan I dan Peralihan II di tiap tahunnya. Pada Maret - Mei dan September - November sedang berlangsung musim peralihan, dimana angin baratan berhembus di atas permukaan Ekuator Samudera Hindia, sehingga Gelombang Kelvin yang terbentuk mengalami pergerakan ke timur dan menimbulkan kenaikan SLA sepanjang penjalarannya 
(Wyrtki, 1973; Sprintall et al., 2000). Dari sebaran spasial SLA, tiap tahunnya tampak pergerakan variabilitas nilai SLA positif di wilayah Ekuator Samudera Hindia lebih tinggi di musim Peralihan I dibandingkan musim Peralihan II.
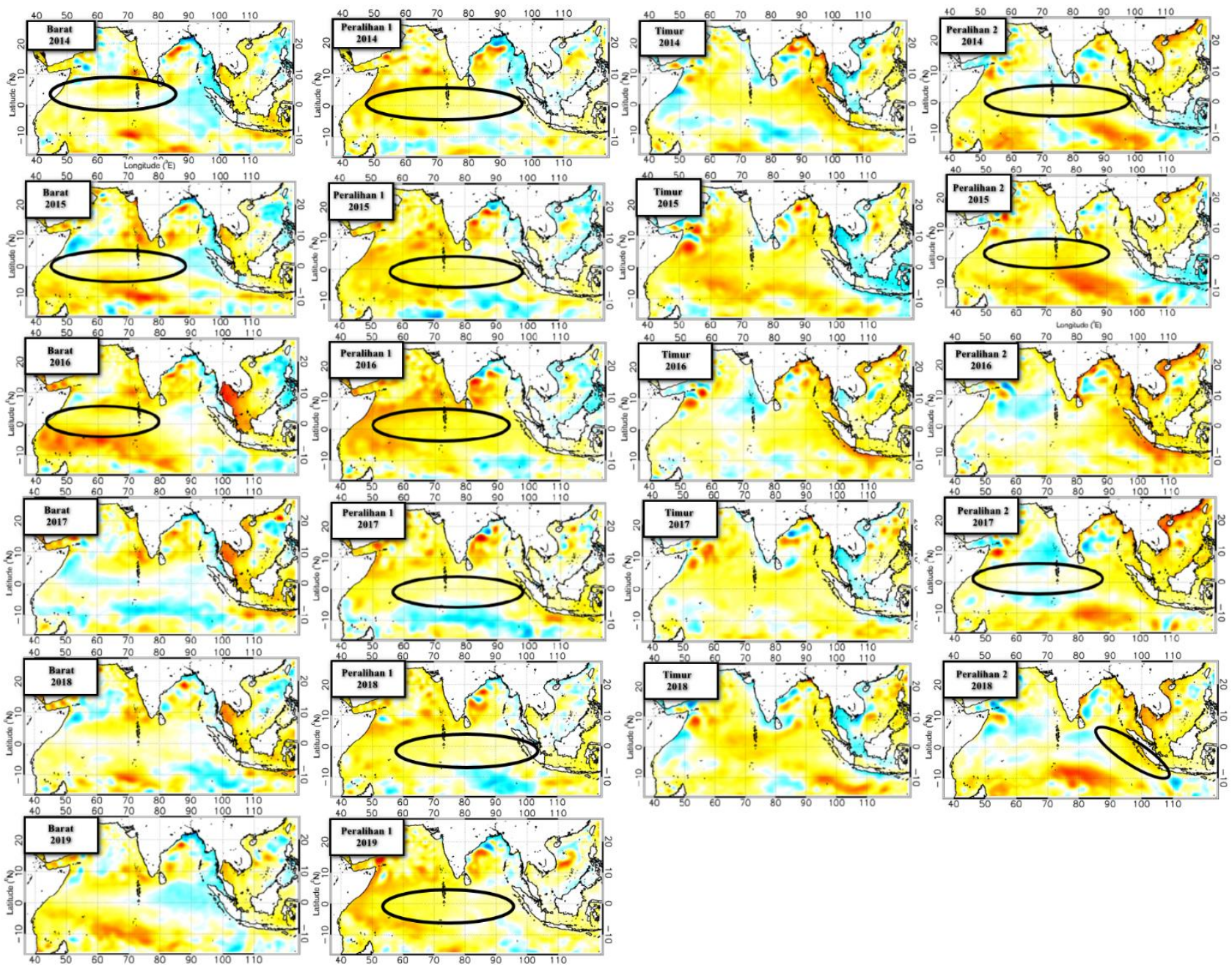

$-0.5$

$-0.3$

$-0.1$

$\begin{array}{llll}0.1 & 0.3 & 0.5 & (\mathrm{~m})\end{array}$

Gambar 2. Variabilitas SLA secara spasial tahun 2014-2019 di Ekuator Samudera Hindia sampai Perairan Selatan Jawa

Gambar 2 menunjukkan bahwa variabilitas SLA positif yang cenderung tinggi didominasi pada musim Peralihan I dan Peralihan II di tiap tahunnya. Pada Maret - Mei dan September - November sedang berlangsung musim peralihan, dimana angin baratan berhembus di atas permukaan Ekuator Samudera Hindia, sehingga Gelombang Kelvin yang terbentuk mengalami pergerakan ke timur dan menimbulkan kenaikan SLA sepanjang penjalarannya (Wyrtki, 1973; Sprintall et al., 2000). Dari sebaran spasial SLA, tiap tahunnya tampak pergerakan variabilitas nilai SLA positif di wilayah Ekuator Samudera Hindia lebih tinggi di musim Peralihan I dibandingkan musim Peralihan II.

Kenaikan SLA di bagian timur Samudera Hindia berdasarkan Dimas et al., (2015) pada musim Peralihan barat ke timur (Peralihan I) didominasi oleh sistem angin. Kecepatan angin sepanjang tahun paling kuat pada saat musim Peralihan I dan arah perambatannya masih didominasi angin musim Barat sehingga mempengaruhi 
pergerakan SLA positif ke timur. Sementara pada angin musim Peralihan timur ke barat (peralihan II) arah perambatannya masih didominasi angin musim Timur sehingga pergerakan SLA positif ke timur berkurang.

Menjadi tempat utama bangkitnya gelombang Kelvin, wilayah ekuator Samudera Hindia memiliki tinggi muka laut yang cenderung tinggi. Rata-rata nilai SLA positif tertinggi di tiap tahunnya berkisar $0,2-0,3 \mathrm{~m}$. Nilai SLA mencapai puncak tertinggi pada bulan Juni 2016 dengan melebihi dari 0,4 m.

Gelombang Kelvin berdasarkan sebaran spasial dari barat Samudera Hindia sampai perairan selatan Jawa tahun 2014 - 2019 dan berdasarkan diagram Hovmöller terdapat 3 kejadian yang terdeteksi. Berdasarkan Dimas et al. (2015), pada musim Barat terjadi pusaran arus eddy di bagian timur Samudera Hindia. Pusaran arus ini terbentuk karena adanya pengaruh angin, tinggi muka laut dibawah pusat angin anti siklon lebih tinggi daripada disekitarnya akibat adanya proses konvergensi, sehingga massa air akan bergerak ke muka air disekitarnya yang lebih rendah dan oleh gaya Coriolis dibelokkan ke kiri di BBS. Muka air dibawah pusat angin anti siklon lebih tinggi daripada daerah pinggirannya akibat transpor Ekman yang bergerak menuju daerah di bawah pusat anti siklon. Karena muka air dibawah pusat anti siklon lebih tinggi daripada daerah pinggirannya maka terjadi perbedaan tekanan antara daerah pusat dan pinggirannya. Perbedaan tekanan ini menggerakkan air dari daerah pusat ke daerah pinggirannya dan dalam gerakannya ini akan mengalami pengaruh coriolis yang membelokkannya ke arah kiri di BBS. Terjadinya pusaran arus eddy menambah pengaruh pergerakan SLA positif ke timur pada musim Barat. Sementara pada musim Timur kebalikan dari musim Barat, pusaran arus eddy mengurangi pengaruh pergerakan SLA positif ke timur. Selain pusaran arus eddy, Arus Khatulistiwa Jawa (AKS) juga mempengaruhi, dimana arus samudera tersebut akan mentransporkan massa air dari timur ke barat pada $10^{\circ}-20^{\circ}$ LS yaitu Samudera Hindia bagian selatan.

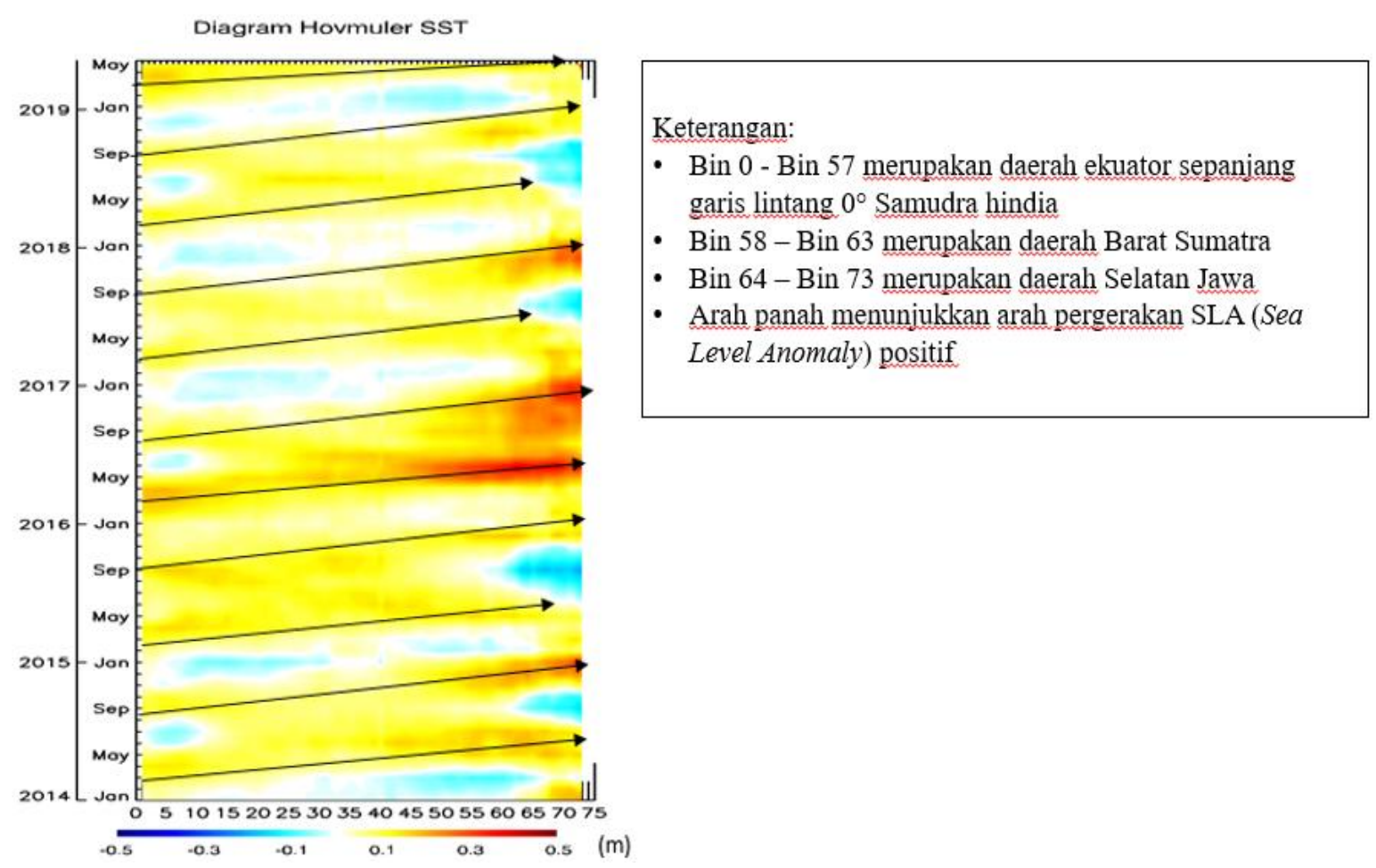

Gambar 3. Diagram Hovmöller SLA di Ekuator Samudera Hindia sampai Perairan Selatan Jawa 


\section{KESIMPULAN}

Dari hasil studi mengenai potensi gelombang Kelvin di perairan selatan Jawa berdasarkan variabilitas SLA (Sea Level Anomaly) bysepanjang tahun 2014 - 2019 dihasilkan kesimpulan potensi gelombang Kelvin yang terlihat berjumlah sekitar 3 kejadian pada musim peralihan I.

\section{DAFTAR PUSTAKA}

Byshev, V. I., V. G. Neiman, Yu A. Romanov, Dan I. V. Serykh. 2012. On El Niño's Impact Upon The Climate Characteristics Of The Indian Monsoon. Oceanology 52(2):147-56.

Delcroix, Thierry, Boris Dewitte, Yves Dupenhoat, Francois Masia, Dan Joel Picau. 2000. Equatorial Waves Dan Warm Pool Displacements During The 1992-1998 El Nifio Southern Oscillation Events: Observation Dan Modeling. 105.

Dimas, R., H. Setiyono, Dan M. Helmi. 2015. Arus Geostropik Permukaan Musiman Berdasarkan Data Satelit Altimetri Tahun 2012-2013 Di Samudera Hindia Bagian Timur. Jurnal Oseanografi, 4 (4): 756 - 764.

Drushka, K., J. Sprintall, dan S. T. Gille. 2010. Vertical Structure of Kelvin Waves in the Indonesian Throughflow Exit Passages. Journal of Physical Oceanography, 40 (9): 1965-1987.

Holton, James R. Dan Richard S. Lindzen. 1968. A Note On 'Kelvin' Waves In The Atmosphere 1. Monthly Weather Review 96(6):385-86.

Matsuno, Taroh. 1966. Quasi-Geostrophic Motions In The Equatorial Area. Journal Of The Meteorological Society Of Japan. Ser. II 44(1):25-43.

Sprintall, Janet, James T. Potemra, Susan L. Hautala, Nancy A. Bray, Dan Wahyu W. Pdanoe. 2003. Temperature Dan Salinity Variability In The Exit Passages Of The Indonesian Throughflow. Deep-Sea Research Part II: Topical Studies In Oceanography 50(12-13):2183-2204.

Sprintall, Janet, Arnold L. Gordon, Ragu Murtugudde, Dan R. Dwi Susanto. 2000. A Semiannual Indian Ocean Forced Kelvin Wave Observed In The Indonesian Seas In May 1997. Geophysical Research 105(17):21730.

Wallace, John M. Dan V. E. Kousky. 1968. Observational Evidence Of Kelvin Waves In The Tropical Stratosphere. Journal Of The Atmospheric Sciences 25(5):900-907.

Wang, Chunzai Dan Robert H. Weisberg. 2001. Ocean Circulation Influences On Sea Surface Temperature In The Equatorial Central Pacific. Journal Of Geophysical Research: Oceans 106(C9):19515-26.

Wirasatriya, A., Y. R. Setiawan, Dan P. Subardjo. 2017. The Effect Of ENSO On The Variability Of Chlorophyll-A And Sea Surface Temperature In The Maluku Sea. Journal Of Selected Topics In Applied Earth Observations And Remote Sensing, 10:5513-5518.

Wyrtki, Klaus. 1973. An Equatorial Jet In The Indian Ocean. Science 181(263-264). 